Kingdom and the United States. This anomaly may occur in all foodstuffs, but it has been noted mainly in milk, where it has been attributed to marked differences in dairying practices.

\section{No Mutations in Kerala}

A SEARCH for possible genetic consequences of the comparatively intense background radioactivity in Kerala, South India, has yielded a negative result. The study and its results are described in a report now published in Britain by the Medical Research Couneil ( $A$ Search for Genetic Effects of High Natural Radio-activity in South India. H.M.S.O. 11s.). Within the limits of its statistical significance, tho study bears on the suggestion, first given prominence in the late 'fifties, that the genetic consoquences of small but ehronic doses of radiation should be most apparent in populations of living things in exceptionally radioactive environments. A report of the com. mittee on radiation appointed by the World Health Organization, and which reported in 1959, was one of several to urge that such exceptional populations should be studied with great care. Kerala commends itself as a site for such an investigation because of its monazite sand, rich in thorium.

The study has been carried out by a team under Prof. H. Gruneberg, honorary director of the Experimental Genetics Research Unit of the Medical Research Council at University College, London. The report explains that the study was concerned with wild populations of the black rat Rattus rattus $\mathrm{L}$., because this animal is the only mammal other than man to occur in large numbers in the region. Wild rats were trapped at eight villages on the narrow coastal strip of monazite sand, and at eight nearby villages away from the strip. A total of 438 rats were trapped at the monazite villages, and 458 at those used as controls. The numbers of males and females were insignificantly difforent. Measurements were made of anatomical quantities such as the sizes of the crowns of molar teeth, which aro substantially independont of age, and of other skeletal dimensions for which it was necessary to make a correction for age. Skoletons were also scrutinized for certain moro or less well-defined variations of shapo, while attempts were made to estimate fertility and pre-natal mortality from the incidence of pregnancy in female rats, and from characteristies of the unborn litters.

The intensity of the gamma-radiation on the coastal strip, equivalent to $1.6 \mathrm{r}$. a year, was seven and a half times that in the control areas inland. Measurements revealed that both populations of rats are heterogeneous, but that thore aro no systematic differences between the two groups that would suggest either systematic genotic differeneos or a larger genotic variance in the more heavily irradiated group. The authors of the report point to four hypotheses consistent with their results--tho existence of a 'threshold' of radiation doses bolow which genetic damage does not occur; the possibility that genetic mutations duo to radiation might be almost exactly balanced by natural selection; the possibility that an increase of genetic variance due to radiation might bo almost exactly counterbalanced by a reduction in environmental variance; and the possibility that accidents of sarnpling may obscure a real effect. An extromoly tentative calculation suggests that a difference of $0 \cdot 3$ per cent in the means of measurement from the two groups might be concealed by sampling errors. The authors echo a statement in an introductory note by the Medical Research Council to the effect that there is nothing in this apparently negative study conclusively to suggest that low doses of radiation have no genetic effects. Because of the way in which gonetic effects may be masked by effects due to the environments or natural selection, however, the authors offer little hope that further studies of this kind will yield decisive results.

\section{Aflatoxin in Malaysia}

RESEARCH in progress at several institutions in Kuala Lumpur has shown that aflatoxin is present in various groundnut products on sale in Malaysia. In view of the social implications and the need for an interdisciplinary approach to them, the Malaysian Scientific Association has set up a committee with the following terms of reference: "To encourage investigation of aflatoxins in Malaysia and to collect and disseminate information on this problem. To formulate recommendations for the reduction of hazards arising from aflatoxins in this country".

\section{Problems of Food Aid}

A STUDY of some of the problems encountered in the organization of food aid to developing countries has been made by D. A. FitzGerald of the Brookings Institution, Washington, D.C. The study is published in a report, Operational and Administrative Problems of Food Aid, the fourth in a series of World Food Program Studies by the Food and Agriculture Organization of the United Nations (Pp. viii+63. Rome: Food and Agrieulture Organization of the United Nations; London: H.M.S.O., 1965. 5s.; I dollar). The study covered the background to food aid from its beginning with the passing of an amendment to the United States Mutual Security Act in 1953, to the establishment of the World Food Programme in 1961 by the United Nations General Assembly. The purpose of the study was to analyse the experience gained in the organization of food aid and to draw conelusions for the guidance of member governments in deciding whether the World Food Program should be continued beyond its original three-year period. Assistance to developing countries has been supplied either as bulk-supply, project-oriented or emergency food aid, the first of these categories being by far the major part of all food aid in the first 6 years. The problems encountered in organizing each of these three types of aid are considered under separate headings.

\section{Electronics Star Catalogue}

THe Smithsonian Astrophysical Observatory has now published in the United States a comprehensive star catalogue giving the positions and proper motions of more than a quarter of a million stars. The Smithsonian Astrophysical Observatory Star Catalog is available either in printed form, occupying four volumes, or as two reels of magnetic tape compatible with IBM 729 units. The books, available at the United States Government Printing Office, Washington, D.C.. cost 20 dollars; the tapes cost 50 dollers, and are to be had from the Smithsonian Astrophysical Observatory.

The availability of the catalogue on magnetic tape is in accord with the extent to which the Institution has relied on computers in the eompilation of the new catalogue. Work began more than 8 years ago and a computer programme was used to correlate information about the positions and proper motions of stars given in various catalogues and to refer these to the Epoch and Equinox $1950 \cdot 0$. In effect, the new catalogue is a combination of several earlier catalogues, including these catalogues: the I'K 4, FK 3, GC, $A G K$ 2, $A G K$ 1, Greenwich $A C$, Yale, Cape, Capo Zone, $M e$ 3, and $M e$ 4. Transforring this mass of information into print was accomplished by means of a Stromberg Carlson computer which was programmed so as to present an image of one page of print at a time on the face of a eathode ray tube. This was then photographed to produce lithographic plates for printing. At the Smithsonian Astrophysical Observatory the information is now being transferred to sky maps which are expected to be complete by this summer. The density of stars is such as to provide an average of six stars per square dogree. The average standard deviation of the position of the stars at the time of their first observation 